\title{
Positioning-Emotions Association of Young Students Using Digital Technology
}

\author{
Wajeeh Daher ${ }^{1,2, *(D)}$ and Osama Swidan ${ }^{3}$ \\ 1 Department of Mathematics Education, Al-Qasemi Academic College of Education, \\ Baqa-El-Gharbia 3010000, Israel \\ 2 Department of Educational Sciences, An-Najah National University, Nablus P400, Palestine \\ 3 Program for Science and Technology Education, Ben Gurion University of the Negev, \\ Beer-Sheva 8410501, Israel; osamas@bgu.ac.il \\ * Correspondence: wajeehdaher@najah.edu or wdaher@qsm.ac.il
}

Citation: Daher, W.; Swidan, O.

Positioning-Emotions Association of Young Students Using Digital

Technology. Mathematics 2021, 9, 1617.

https://doi.org/10.3390/

math9141617

Academic Editor: Paula Catarino

Received: 31 May 2021

Accepted: 5 July 2021

Published: 8 July 2021

Publisher's Note: MDPI stays neutral with regard to jurisdictional claims in published maps and institutional affiliations.

Copyright: (C) 2021 by the authors Licensee MDPI, Basel, Switzerland. This article is an open access article distributed under the terms and conditions of the Creative Commons Attribution (CC BY) license (https:/ / creativecommons.org/licenses/by/ $4.0 /)$.

\begin{abstract}
Researchers in social semiotics have shown students' emotions to be associated with their positioning, an association which contributes to students' cognitive processes and, therefore, to their learning. Nevertheless, this association between emotions and positioning, especially with regard to very young students, has not been extensively investigated with qualitative methods. The present work considers the positioning-emotions association in the context of third-grade students using digital technology to study relationships among quadrilaterals. The entire learning process of eight students, divided into four pairs, was recorded on video; the transcripts were then analyzed using qualitative and quantitative methods to understand the relationship between positioning and emotion constructs. A chi-square test was run for the transcribed data to find the correlations between constructs for positioning and emotions. We found a strong connection between outsiderness and boredom and between leadership confidence; moderate connections were found between outsiderness and powerless, help-seeking and confusion, and collaboration and interestedness. We used the discursive framework for connecting positioning with emotions to encode the data and triangulate our qualitative and quantitative findings. By these means, we were able to draw conclusions regarding the role of digital technology in determining students' positioning and of the teacher in modifying undesirable positioning and its associated emotions.
\end{abstract}

Keywords: positioning; emotions; primary schools; relationship; digital technology

\section{Introduction}

Emotions can have a profound impact on how students learn mathematics. As Goldin [1] has emphasized, learning mathematics is not a purely cognitive process, and understanding the influence of the affective domains is a critical part of understanding students' learning of mathematics. Goldin [1] notes, moreover, that: "certain patterns or regularities in emotions and their influence seem to stand out in mathematics education," citing as an example the relation of math anxiety to students' perceptions of their mathematics ability and performance (p. 393). In another example, Pekrun et al. [2] found that students who enjoyed and took pride in math had better achievements, while students who experienced anger, anxiety, shame, boredom, or hopelessness had lower achievements.

Students' emotions in the mathematics classroom have attracted researchers' attention due to their relationship with other aspects of students' learning of mathematics, especially the cognitive aspect (e.g., [3,4]), the psychological aspect (e.g., [5], the social aspect (e.g., [6,7]) and the affective aspect (e.g., [8]). This interest in emotions has extended to students' learning with technology (e.g., [9-11]). Enriching our understanding of emotions can help us understand how they influence and are influenced by other educational variables, which could enable us to make better decisions regarding the promotion of students' success in mathematics. 
The last decade has also seen an increased interest amongst researchers in students' positioning, or the "fluid parts" that students find themselves "taking up or being assigned ... to play" during social interactions ([12], p. 374). As Evans, Morgan and Tsatsaroni [6] emphasize, "positioning is not permanent" (p. 210). Rather, the "positions" available in a given situation are "the various roles that may be adopted, together with their possibilities for action and relationships with other participants" (ibid). Positions in learning situations are either claimed by the learners or given to them by the teacher in the context of classroom norms [13]. A student can take on the position of leader, for example, by proposing a course of action to fellow students ("I have an idea, let's do this ... ") or by taking control of the mouse when using a digital tool. Alternatively, teachers can attempt to alter positions adopted by students instinctively-either by assigning students a specific and explicit role, or more generally, by encouraging a passive student to participate more actively and collaboratively.

Studies of positions in the learning experience have already shown that how students are positioned can influence their emotional state, and consequently their ability to learn [11,12]. Understanding the particulars of the relationship between positioning and emotion could therefore benefit mathematics educators, allowing them to more productively manage students' emotions by strategically manipulating their positioning. To that end, the study presented here sought to explore the relationships between the emotions of elementary school students and their positioning as they learn geometrical concepts via digital technology.

\section{Literature Review}

\subsection{Positioning and Its Role in Students' Learning}

The term "positioning" originates in discursive psychology, which assumes that psychological phenomena are rooted in interpersonal discursive processes and can therefore be interpreted in terms of features of the discourse. The discursive framework views learning as participatory, considering each participant's role in the learning process in terms of their changing participation in a network of relations within a community [14]. Participation in this community depends on its participants' respective skills, and their social positions in the community [15]. Examining positioning, from a discursive standpoint, means looking closely at what people are doing with their talk, from what perspective they are speaking [16]. The participants in a discourse are positioned according to the rights and duties they acquire or that have been imposed on them $([17,18])$. Examples of positions in the classroom are: leader, follower, collaborator, outsider, and insider.

Students' positioning in learning activities can be assessed in a variety of ways [19]. One approach is the analysis of pronoun use, which can indicate how people align others and/or themselves. The use of "we" instead of "you" positions the speaker as part of a group that includes the listener. On the other hand, the use of "he" instead of "you", when the referent person is present, indicates that the goal of the speaker is to inform an audience about the referent person. In this case, the speaker and the audience are part of a group that is commenting on the referent person.

Several studies of primary school students' positioning have shown how the power relations that are produced by positioning can influence learning. For example, Ritchie [20] used the positioning framework to investigate the dynamics of sixth grade students' interactions within same-gender and mixed-gender groups during science activities, showing that opportunities for learning science were denied to two female students because the two did not negotiate productive story lines within their groups. Tait-McCutcheon and Loveridge [21] examined how two primary school teachers taught the same mathematics lesson to their lowest ability group of second and third grade students. They analyzed how the positioning of the teacher and students, and the developing storylines and social acts from that positioning, led to inequitable opportunities for active and collaborative participation in the mathematics lesson. They concluded that the differences in pedagogy suggest 
that the way teachers positioned themselves and their students was more influential than the resources with which they were teaching.

\subsection{Analysing the Relationship between Positioning and Emotions: The Discursive Framework}

The goal of this study was to identify the relationship between the emotions and positioning constructs that may emerge when elementary school students learn geometrical concepts using digital tools. Because this study was designed to identify emotions and positioning, and the relationship between them, we framed it using the "the discursive framework" [22], which is based on social semiotics. Jewitt and Henriksen [23] describe social semiotic as using linguistic means to study "social relations, power, signification, the interests of sign makers, the imagined audience, and the social purposes realized by texts" (p. 146). Specifically, the discursive framework draws connections between the positions available for students in their learning of mathematics and their emotions during that learning. Thus, this use of the discursive framework of Morgan et al. [22] is due to our concern with the relationship between two constructs: positioning and emotions. Using this specific discursive framework as a theoretical tool made possible a thorough analysis of the relationship between the students' positioning and their emotions.

Morgan et al. [22] in their "discursive framework" argue that the positions held by students within a learning group dictate the emotions they are likely to experience. For example, being positioned as knowledgeable could result in positive emotions, while being positioned as ignorant or as a novice could result in negative emotions. In this way, learners' emotions could be considered as shaped by the power relations that are drawn between them. The discursive analysis of students' emotions and positioning consists of two phases: the structural and the textual. In the structural phase, learners' positionings are analyzed. Morgan, Evans and Tsatsaroni divide the positions addressed in the structural analysis into the following binary categories (in each of which the former is more powerful than the latter): helper and seeker of help, collaborator and solitary worker, director of activity and follower of directions, evaluator and evaluated, insider and outsider. Though students can hold multiple, overlapping positions at once, each utterance was coded exclusively, based on the most dominant position being represented. Thus, for instance, a leader who was a collaborator in the group was coded a leader, as leadership could be expressed through collaboration.

The second phase of discursive analysis (the textual analysis) has two functions: (a) showing how positions in social interactions are actually taken up or claimed by the participants, and (b) providing indicators of emotional experience. We performed the second function based on the variety of emotions that have been defined and described by previous research on the topic of emotion and learning (e.g., [2,24]).

The textual analysis has two stages. In the first stage, the focus is to identify the interpersonal aspects of the text that establish the positions of the participants. Indicators at this stage include reference to self and others, reference to valued statuses (e.g., claiming understanding or correctness), modality (indicating degrees of un/certainty), hidden agency (e.g., passive voice) or repetition. The second stage of the textual analysis attends to indicators of emotional experience generally understood/used within the (sub) culture: direct verbal expression (e.g., "I feel anxious"), use of particular metaphors (e.g., claiming to be "coasting"), emphasis by words, gesture, intonation, or repetition (indicating strong feelings), body language (e.g., facial expression or blushing).

\subsection{Positions and Emotions in the Presence of Technology}

Recently, researchers have become interested in exploring the role of digital technology in shaping students' positioning and emotions [25-28]. Daher et al. [25] used qualitative methods to examine the positionings and emotions related to them of a group of three 15-year-old students discussing, while utilizing technology, the definition of terms associated with the topic of "the circle". The research findings indicated that the students used Dynamic Geometry Software (e.g., GeoGebra) to manage the negative emotions caused by 
feeling powerless due to not being able to agree on the definition of the geometric concepts. The group members overcame their negative emotions by manipulating the geometric objects in GeoGebra and thus arriving at agreed definitions of the geometric concepts. Thus, the technological tool empowered the group members' positions, changing their negative emotions to positive ones. Furthermore, the technological tool not only empowered the group's position as a whole, but also empowered the positions of members who worked with it. The present paper differs from the previous paper in two respects. First, Daher et al. [25] used only qualitative methods, while the present paper uses a combination of qualitative and quantitative methods. Second, the focus in the previous study was identifying the positioning and emotions that were present and pertinent in a single case (analytical generalization), while the present study focuses on the significance of the relationships between positioning and emotion constructs in multiple cases (statistical generalization).

\subsection{The Digital Tool Used in the Study and the Task Given to the Students}

The digital tool used in this study is the 'Exploring Properties of Triangles and Quadrilaterals' (EPTQ) applet [29]. EPTQ is a dynamic geometry software that provides an environment in which students can explore and observe the properties of triangles and quadrilaterals by manipulating the sides, angles, and type (Figure 1a). Thus, EPTQ could be considered a mindtool, which is a computer application that, when used by learners to represent what they know as a process to explore what they do not know, necessarily engages them in critical thinking about the content they are studying [30]. The EPTQ interface includes three sections: (a) the quadrilateral names section, which includes icons bearing the names of the different types of quadrilaterals, (b) the quadrilateral properties section, which includes icons for constructing different quadrilaterals that satisfy the property highlighted on the icon, and (c) the exploration section, where the quadrilaterals are constructed and can be dragged. The EPTQ is an interactive digital tool in which clicking any icon in the applet will reflect on the other parts of the EPTQ. For example, clicking

the icon kiten in the exploration section will make a kite appear, and highlight all the icons that satisfy the kite properties in the quadrilateral properties section (Figure 1b). Students can drag and rotate the shape on the exploration section, and the shape will retain its geometric properties.
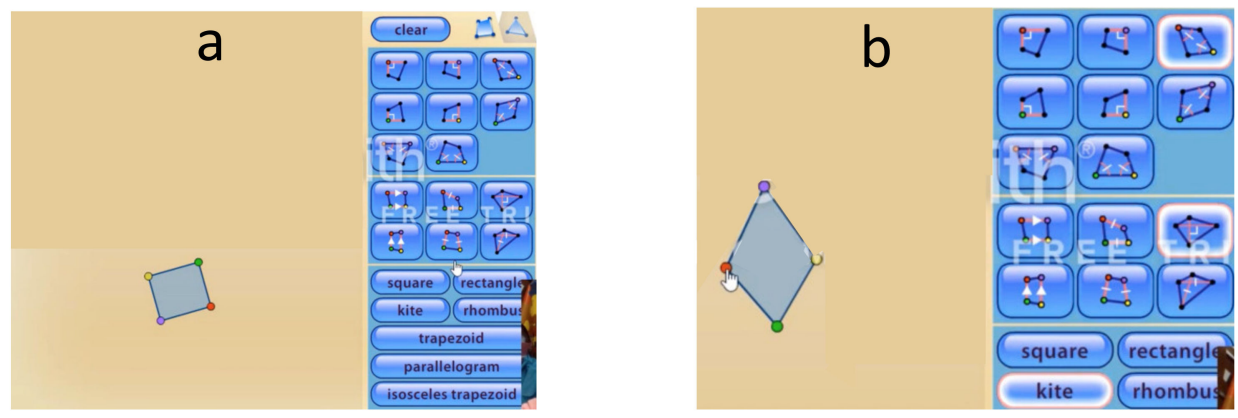

Figure 1. (a) EPTQ interface; (b) EPTQ interface when the kite icon is clicked.

Each pair of students was then given a written task, as well as additional verbal instructions explaining the task before the students started their exploration. The task asked the students to explore the hierarchical relationship between the quadrilaterals and explain to one another the possible relationships between the quadrilaterals on the screen. The written task was composed of four subtasks. The first subtask, which was designed to familiarize the students with the applet and its capabilities, asked the students to interact with the applet and to create different geometrical shapes with it. The second subtask asked the students to create a rectangle and use the applet to manipulate its shape, which allowed them to observe the invariant features of rectangles as they manipulated them. The third subtask, which aims at exploring the hierarchical relationship between rectangles and 
parallelograms, asked the students to create rectangles by manipulating parallelograms, and to observe the common geometrical properties that are kept when they manipulate the shapes. Like the third subtask, the fourth also asked the students to explore and observe what properties were maintained as they manipulated different quadrilateral shapes, such as, parallelogram, rhombus, kite, rectangle, and square. Figure 2 illustrates the second and the third subtasks that were given to the students.

Construct a rectangle by clicking the 'rectangle, and manipulate it by dragging the vertices and the sides. You can rotate or stretch the shapes, but they will retain particular features.

- What is similar about all the figures produced by the dynamic rectangle?

Construct a parallelogram by clicking the a parallelogram, and manipulate it by dragging the vertices and the sides. You can rotate or stretch the shapes, but they will retain particular features.

- What is similar about all the figures produced by the dynamic parallelogram?

- What common characteristics do parallelograms and rectangles share?

- How do rectangles differ from other parallelograms?

Figure 2. The second and third subtasks that were given to the students.

The solution of the task was communicated verbally between each pair of students, which allowed the researchers to examine their positioning and emotions by observing their interactions throughout the solution process.

\section{Method}

The study reported in this paper is a part of a larger research project designed to explore the relationships between affective and social constructs of elementary students as they learn geometrical topics with digital tools. In this paper, we focus on four pairs of students (eight students in total) to report our findings about the relationships between students' positioning and their emotions.

Relationships between the different aspects of students' learning, (e.g., cognitive, social, affective, and meta), have been studied using different research methods-both qualitative or quantitative. The qualitative methods, such as the discursive framework, reflect the efforts of researchers in mathematics education to carry out in-depth analyses of these relationships during teaching and learning (e.g., [6,13]), while quantitative methods rely on data from students' self-reported questionnaires (e.g., [31,32]). Studies that use an exclusively qualitative approach are limited in their ability to test hypotheses based on theoretical frameworks, or in their ability to generalize findings beyond the small number of analyzed cases [33]. Studies that adopt questionnaire-based measures, in contrast, must be carefully constructed to ensure they are appropriate for student's age, and even then, very young children may struggle to provide reliable self-reports. Moreover, questionnaires do not provide in-depth information about how emotions manifest in a mathematical learning or performance situation. With these limitations in mind, this study combined qualitative and quantitative methods to understand the relationship between emotions and positioning constructs, basing our analysis on data collected from the observation of live classroom situations, which we first analyzed qualitatively using Morgan et al.'s [22] discursive framework, and then subjected to additional statistical analysis.

\subsection{Participants and Procedure}

The present study focused on eight third grade students from a public school in Israel. The participants, all high achievers in mathematics, volunteered to participate in 
four after-school meetings of approximately $25 \mathrm{~min}$ each. The meetings were conducted at a computer lab at the students' school, and each was devoted to the completion of one of the four sub-tasks detailed above. All of the students' parents signed consent forms and all of the students were present for all four meetings. The students' names used in this study are pseudonyms.

At the time the meetings took place, the participants had already learned the concepts of square, rectangle, kite, rhombus, parallelogram. These concepts had been taught based on a textbook available to elementary school students in Israel. They were also familiar with the relationships between segments, such as perpendicular, parallel, and congruence of segment, which had been part of their previous study within the framework of the formal school curriculum.

Each pair of students shared one computer, working with the same partner during all four meetings. The teacher introduced the students to the applet and showed them how to work with it. She explained, for example, how to create quadrilaterals and how to drag and stretch them. The teacher intervened to boost the learning process when it was stuck. The second author was present as an observer and only provided technical clarifications when needed.

\subsection{Data Collection and Analysis}

To collect the data, we video-recorded all of the student pairs in each session, as they were solving the task, including the computer screens upon which they were working. In total, we video-recorded 12 clips, documenting the entire learning process. The average film length is $25 \mathrm{~min}$ (mean $=25 \mathrm{~min} ; \mathrm{SD}=4 \mathrm{~min}$ ) and the total number of learning hours for all the participants was thus $5 \mathrm{~h}$ ).

As mentioned above, we applied a mixed method to identify relationships between emotion and positioning. First, the data was analyzed qualitatively. We began by watching the videos repeatedly, transcribing the video recording and reading the transcripts to detect the indicators of emotions and positioning of the students. Next, we wrote descriptions of each pair's work. The transcripts and descriptions of all four pairs of students were used to code the students' emotions and positioning based on the indicators detected earlier. We examined potential indicators in each utterance first, and later the specific positions/emotions that emerged from those indicators. The coding process resulted in a list of emotions and positioning. Table 1 shows positions and their indicators [34].

Table 1. Description of positions.

\begin{tabular}{|c|c|c|}
\hline Position & & Indicators \\
\hline Leader & - & $\begin{array}{l}\text { She/he is frequently deferred to (mathematically) } \\
\text { She is often granted authority to decide whether the } \\
\text { mathematical work of the group was correct. }\end{array}$ \\
\hline follower & - & $\begin{array}{l}\text { She/he frequently followed directions by a leader, as } \\
\text { directions regarding the accurateness of the mathematical } \\
\text { work performed by her/him. }\end{array}$ \\
\hline Solitary worker & - & $\begin{array}{l}\text { She/he went through periods of individual work during } \\
\text { her/his work to define geometric concepts. }\end{array}$ \\
\hline Collaborating participants & - & $\begin{array}{l}\text { They worked together, as for example completing an idea } \\
\text { together. }\end{array}$ \\
\hline "Helper" participant & - & $\begin{array}{l}\text { When the mathematical talk was asymmetrically organized, } \\
\text { and a participant instructed other participants about what } \\
\text { to do. } \\
\text { Uncritical uptake of ideas. }\end{array}$ \\
\hline Needing-help participant & - & She/he asked for help from another member of the group \\
\hline
\end{tabular}


We described above the indicators of emotions: the use of language explicitly referring to an emotion (e.g., "happy," "sad"); the use of a gesture or movement associated with an emotion (e.g., a hand raised in the air to indicate accomplishment or content); the presence of a facial expression that suggests an intensity of feeling (e.g., a furrowed brow).

Table 2 shows an example on analyzing positions and emotions. In the present research, emotions and positioning are those related to mathematics learning. To ensure the reliability of the qualitative data analysis, we (the paper's two authors) independently coded the data, after which we discussed the analytical processes that each of us performed.

Table 2. Coding emotions and positioning in an observation.

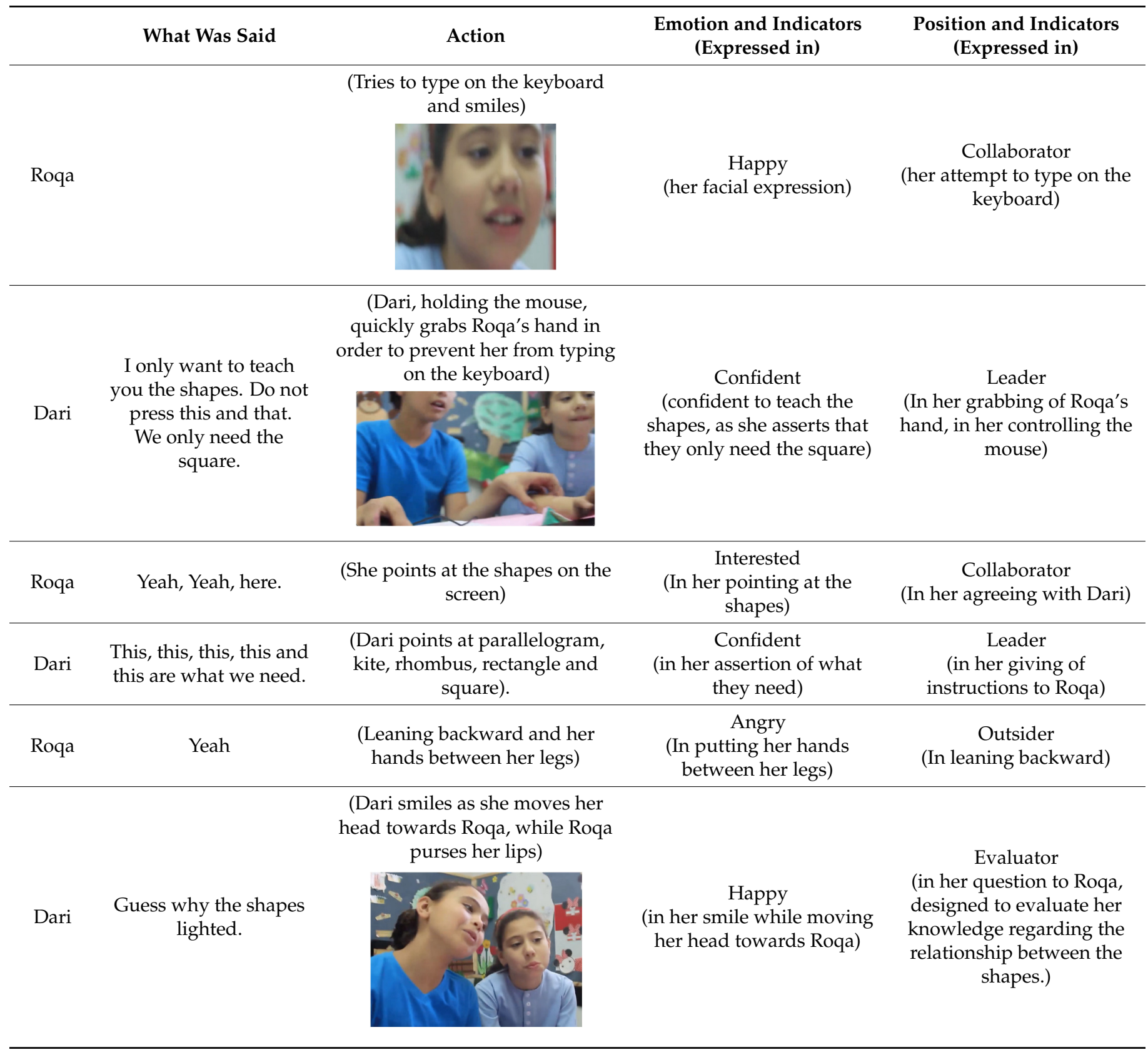


Table 2. Cont.

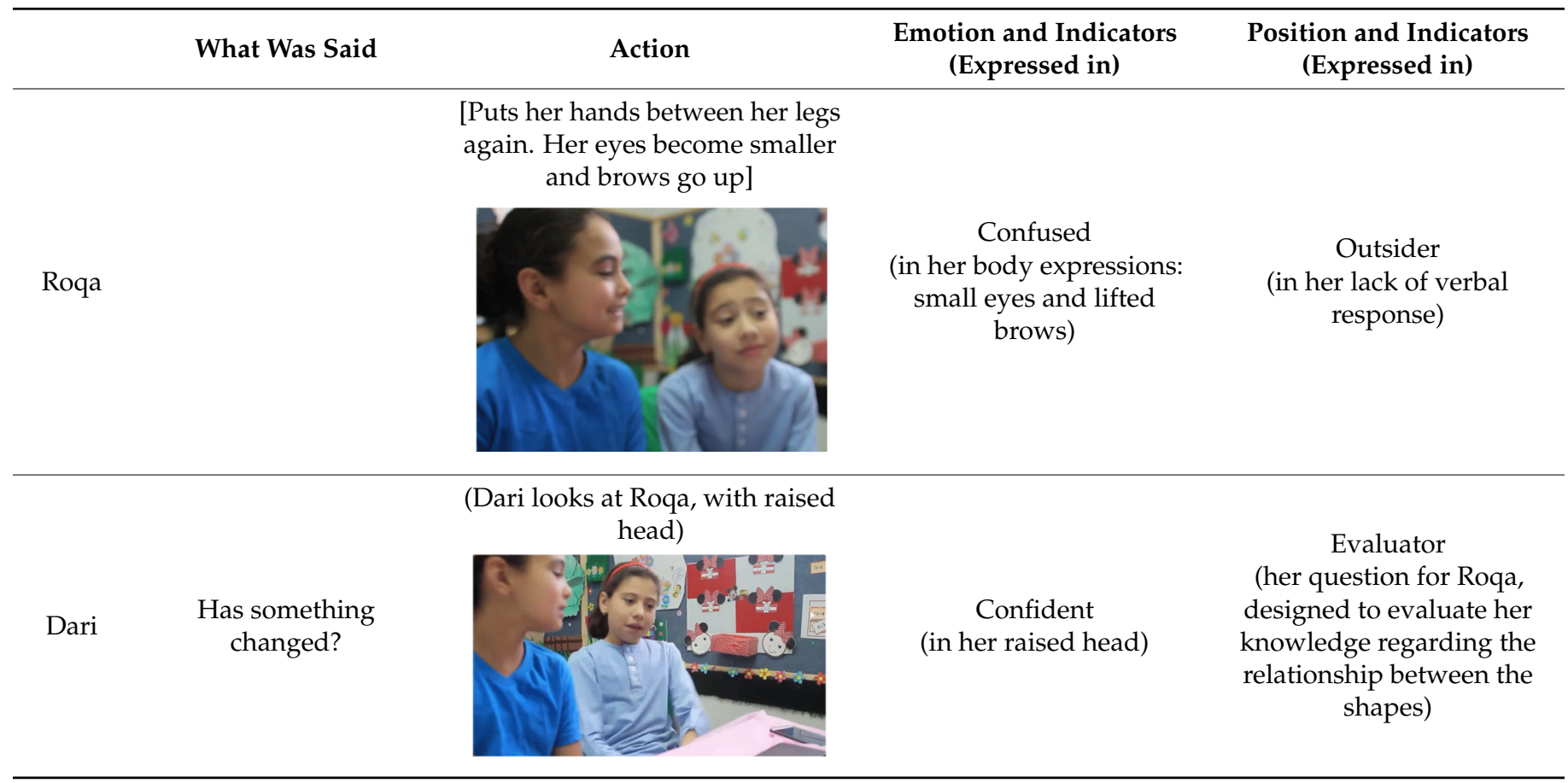

Our unit of analysis was the students' utterances. We defined an utterance as any instance of uninterrupted speech or action on the part of the students. Thus, the students' utterances begin when they begin their speech or action and end when another students speech or action starts. In total, we collected and analyzed 1986 utterances from four pairs of elementary students as they performed geometrical tasks with digital tools. Initially, we coded each utterance, distinguishing them into different types of positioning and emotions (as shown above). Then we analyzed the data quantitatively to find significant correlation between emotion and positioning constructs. In order to guarantee the trustworthiness of the research analysis, the agreement between judges was used [35]. Two expert transcribers separately transcribed $25 \%$ of the transcription and identified the categories of positions and emotions. The agreement between judges was between 0.825 and 0.874 which is considered a fair value for agreement between judges, as it is considered acceptable when it is $70 \%$ or greater [36].

To determine if there is a significant relationship between a particular emotion and a particular positioning of the students, we performed a chi square test using SPSS 25.00. To determine the strength of associations between the identified significant relationships, we examined the correlation between the significant relationships using phi level of association, based on Rea and Parker [37] 's recommended conventions. Below we summarize the phi level ([33] p. 203): negligible association ( 0.00 and under 0.10$)$, weak association ( 0.10 and under 0.20$)$, moderate association $(0.20$ and under 0.40$)$, relatively strong association $(0.40$ and under 0.60$)$, strong association ( 0.60 and under 0.80$)$, and very strong association ( 0.80 to 1.00$)$.

\section{Results}

The constructs that emerged from the qualitative analysis regarding students' positioning were: leader, evaluator, collaborator, seeking help, and outsider. At the same time, the constructs that emerged regarding students' emotions were: powerless, bored, confused, angry, interested, happy and confident. Table 3 shows the phi values of the magnitude of association between the variables from the positioning aspect and the variables from the emotions aspect. 
Table 3. Phi effect size values of the magnitude of associations between the variables from the positioning aspect and the variables from the emotions aspect.

\begin{tabular}{cccccccc}
\hline & Powerless & Bored & Confused & Angry & Interested & Happy & Confident \\
\hline Leader & $-0.10^{* * *}$ & -0.06 & $0.07^{* *}$ & $0.07^{*}$ & $0.08^{* *}$ & $0.06^{*}$ & $0.52^{* * *}$ \\
Evaluator & -0.01 & -0.01 & $0.06^{*}$ & $0.10^{* *}$ & -0.02 & -0.01 & -0.04 \\
Collaborator & 0.04 & -0.05 & $0.15^{* * *}$ & 0.01 & $0.28^{* * *}$ & 0.02 & -0.00 \\
Help & $0.27^{* * *}$ & $0,10^{* *}$ & $0.31^{* *}$ & 0.05 & $0.09^{* *}$ & -0.03 & $-0.12^{* * *}$ \\
seeker & $0.31^{* * *}$ & $0.77^{* * *}$ & -0.01 & $0.16^{* * *}$ & $0.07^{*}$ & -0.03 & -0.06 \\
Outsider & ${ }^{*} p<0.05^{* *} p<0.01^{* * *} p<0.001$. \\
\hline \multicolumn{7}{c}{}
\end{tabular}

Table 2 shows a significant and strong relationship between being an outsider and being bored, and a significant and relatively strong relationship between being a leader and being confident. At the same time, it also shows a significant and moderate relationship between the pairs: being a collaborator and being interested, feeling powerless and seeking help, feeling confused and seeking help, and feeling powerless and being an outsider.

\subsection{Leader/Confident Relationship}

The example below represents the relationship between the leader/confident constructs. Leadership is a positioning construct which is represented by one student taking action to lead other students. Indicators are: The use of imperative statements (e.g., "Guess why the shapes lit up"), the use of the first-person pronouns (e.g., "I only want to teach you"), or bodily actions aimed at having control (e.g., grabbing the mouse). Confidence is an emotion construct, which we define in this paper as a feeling or consciousness of one's powers. Indicators are: repeated use of determining statements (e.g., "I only want to teach you"; "this is what we need"), bodily actions (e.g., raising one's head).

A chi-square test of independence showed that the relation between these variables was significant, $\chi 2(1, N=1986)=375.084, p<0.001$. Students with more confidence were more likely to show leadership than were students with less confidence. Phi value was 0.519 , indicating a relatively strong correlation between confidence and leadership.

The episode below illustrates the relationship between leadership and confidence. In this episode, Dari leads the exploration process by instructing her classmate and then asking her rhetorical questions.

1 Roqa: (Tries to type on the keyboard)

2 Dari: I only want to teach you the shapes (..2..). (Dari quickly grabs Roqa's hand in order to prevent her from typing on the keyboard) Do not press this and that. We only need the square.

3 Roqa: Yeah, Yeah, here.

4 Dari: This, this, this, this and this are what we need (Dari points at parallelogram, kite, rhombus, rectangle and square-(Figure 3a)).

5 Roqa: Yeah

6 Dari: Guess why the shapes light up. (Dari moves her head towards Roqa, while Roqa puts her lower lip under her upper lip-(Figure 3b))

7 Roqa: Yeah

8 Dari: (Dari clicks on the rectangle icon and looks at Roqa, with raised head(Figure 3c)) Has something changed? 
a

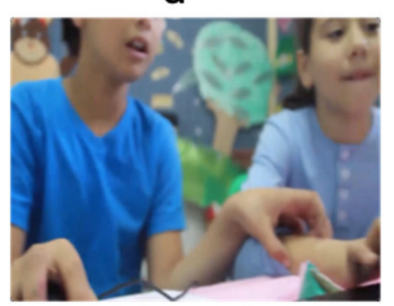

b

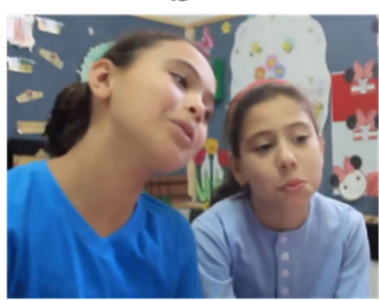

C

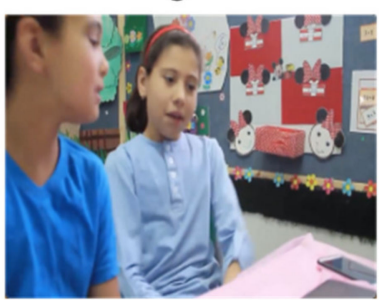

Figure 3. (a) Dari quickly grabs Roqa's hand in order to prevent her from typing on the keyboard; (b) Dari moves her head towards Roqa, while Roqa purses her lips; (c) Dari clicks on the rectangle icon and looks at Roqa, with raised head.

When Dari and Roqa worked on the task, Dari claimed reflexively the position of a leader, as shown in the line number of the dialogue (R1-R8). At the beginning (R2), she led Roqa, telling her which geometric shape to look at. This reflexive positioning as leader was accompanied by the emotion of confidence, as expressed in Dari's emphasizing which shapes the group should focus on. This also happened later (R4), when she led Roqa by pointing at the four quadrilaterals in the interface of the applet. Dari talked with determination ("[these] are what we need"), which is an expression of her confidence in her leadership. Dari continued to claim the reflexive position of leading (R6) by asking Roqa to tell her why the shapes were lit. Here too, this reflexive positioning was accompanied with the emotion of confidence, as indicated by Dari's head movement and her use of the verb "guess" which indicates that Dari already knew why the shapes were highlighted. Then, as though she thought that Roqa did not understand her question, Dari clicked the "rectangle" icon to change the lighted shapes, then she led Roqa forward (R8) by asking her "Has anything changed?" Dari asked the question with a raised head, as if showing off her capabilities, in which she was confident.

\subsection{Outsiderness/Boredom Relationship}

The following transcript discusses the relationship between the outsiderness/boredom constructs. Outsiderness is a positioning construct that we identify when a student does not seem to belong (physically or mentally) to the particular group. Indicators are: Moving away from the group's members and looking aside, looking at the classroom ceiling without reacting to the group discussion, not reacting to a classmate's requests. Boredom is an emotion construct, which we define in this paper as a state of disinterest. Indicators are expressing the feeling directly (e.g., "I am bored"), direct questions about the duration of class (i.e., "when will the class end?"), bodily actions (e.g., yawning; setting the head on the desk).

A chi-square test of independence showed that the relation between these variables was significant, $\chi 2(1, N=1038)=619.508, p<0.001$. Students who were outsiders were more likely to show boredom than students who are insiders. Phi value was 0.766 , indicating a strong relation between outsiderness and boredom.

The following episode illustrates the relationship between outsiderness and boredom. The teacher sees that Roqa (the student sitting on the left-(Figure 4) is an outsider. She intervenes to get Roqa back to the collaboration.

69 Teacher: Press on the kite Roqa.

70 Roqa: On the kite?

71 Dari: The kite under the square

72 Roqa: Where? (Roqa puts her hand in front of her head-(Figure 4a))

73 Teacher: What did I ask, Roqa?

74 Roqa: (Roqa, bored, holds the mouse and yawns-(Figure 4b))

75 Dari: To draw a square from the kite.

76 Teacher: Move closer to each other and discuss the matter.

77 Dari: (Takes the mouse from Roqa) 
78 Roqa: (Still yawning, Roqa puts her hand on her eye and leans on Dari's shoulder(Figure 4c))

a

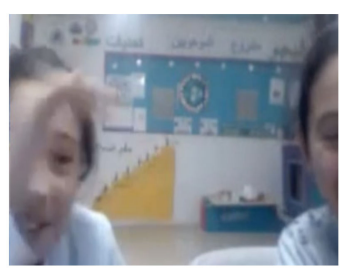

b

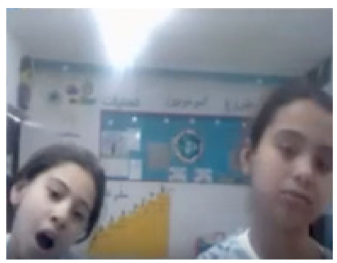

$\mathrm{C}$

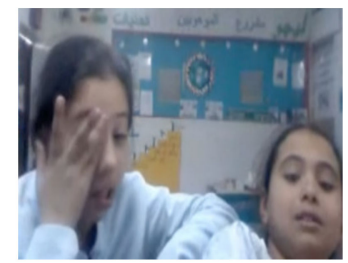

Figure 4. (a) Roqa (left) puts her hand in front of her head; (b) Roqa, bored, holds the mouse and yawns; (c) still yawning, Roqa puts her hand on her eye and leans on Dari's shoulder.

At the beginning of this section, Roqa reflexively assumed the position of an outsider (while Dari was interacting with the computer, Roqa sat at a distance, yawning, rubbing her eyes), so the teacher tried to position her interactively as an insider by asking her to be more involved (R69-R72). Despite this interactive positioning by the teacher, Roqa was reluctant to do so, which made Dari, the other group member, assign her the interactive position of needing help. Dari performed this interactive positioning by directing Roqa regarding the place of the geometric shape. Even this direction did not help Roqa to position herself reflexively as an insider, as represented by her lack of interest in participating in exploring the geometrical shapes. This lack of interest was indicated by putting her hand in front of her eyes as if she was looking at the geometrical shape, which was probably done to attempt to comply with the interactive positioning of the teacher and the other group member (R72). Roqa's outsiderness made the teacher try to intervene once more to assign her an interactive position of insider in the group's learning (R73). Roqa's reflexive positioning of outsiderness was accompanied by boredom, as indicated by her yawning and leaning backward (R74). Roqa did not perform the teacher's request, which made the teacher ask Dari to come closer in order to make her claim an interactive positioning of insider (R76). In spite of these attempts by the teacher and the other participant, Roqa did not collaborate, meaning she continued to claim the reflexive positioning of an outsider. She did this by rubbing her eye, expressing her outsiderness and her accompanying boredom with solving the task (R78).

\subsection{Outsiderness/Powerlessness Relationship}

Powerlessness is an emotion construct, defined here as the feeling of lacking the capacity or the resources to act. Indicators are: Verbally expressing one's inability to do actions (e.g., "I have no way to do that", "I did my best, but unfortunately I was not able"), bodily actions (e.g., opening the arms and putting one lip over the other, leaning backward and looking up at the ceiling).

A chi-square test of independence showed that the relation between these variables was significant, $\chi 2(1, N=1038)=100.286, p<0.001$. Students with more powerlessness were more likely to be outsiders than were students with less powerlessness. Phi value was 0.310 , indicating a moderate relation between outsiderness and powerlessness.

The episode that follows illustrates the relationship between outsiderness and powerlessness. The episode starts with an answerable question asked by the teacher: "what are the common properties of parallelogram?" Afterward, the teacher asks the students a challenging question that considers the hierarchical relationship between the parallelogram and the rectangle.

5 Teacher: What are the common properties of the parallelogram and the rectangle? (..2..) What are the properties of the parallelogram?

6 Ali and Sawe: It has four sides. And every two opposite sides are equal.

7 Teacher: How are the properties of the rectangle derived from the properties of the parallelogram? 
8 Sawe: You mean what remains the same in both shapes? (Ali turns his head aside (Figure 5a))

9 Teacher: Yes, which properties remain the same.

10 Ali: (Ali leans backwards while looking aside. Sawe looks at the screen-(Figure 5b)).

11 Sawe: What is your opinion, Ali?

12 Ali: I do not know. (Puts his hand on his face, which expresses powerlessness)

a

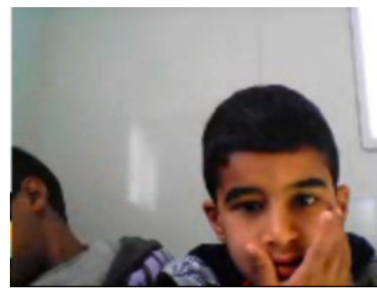

b

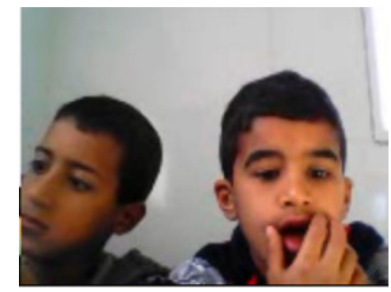

C

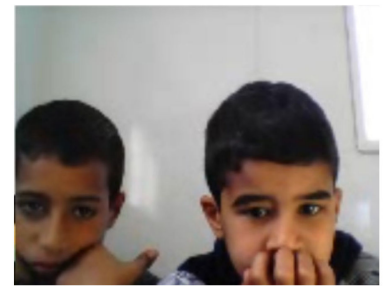

Figure 5. (a) Ali (left) turns his head aside; (b) Ali leans backwards while looking aside as Sawe looks at the screen; (c) Ali puts his hand on his face, expressing powerlessness.

At the beginning of the excerpt, when the lesson required remembering past mathematical content and he knew the answer to the question asked by the teacher, Ali claimed the reflexive position of a collaborator (R5-R6). When the focus of the lesson turned explorative and he did not know the answer to the question (R7), he felt powerless and claimed the reflexive position of an outsider (R8). Sawe noticed that Ali disengaged, so he encouraged him to engage in the explorative activity (R11), i.e., to claim the interactive position of an insider. However, Sawe's intervention did not change Ali's reflexive outsiderness, as he continued to find the activity difficult (R12). This outsiderness resulted in feeling powerless, as expressed by Ali putting his hands on his face (R12) and by his articulation of the sentence "I do not know", in a quiet voice.

\subsection{Seeking Help/Confused Relationship}

The following example represents the relationship between the seeking help/confused constructs. Seeking help is a positioning construct, which we define as one student taking action to obtain an answer from the teacher or another student, usually more expert. Indicators are: Verbal expressions such as "I do not know, could you help me?", "Does somebody know the answer?" or bodily actions such as looking at a classmate and waiting to get hints. 'Confusion' is an emotion construct, defined in this paper as the state of being uncertain, or finding something difficult to understand. Indicators are: Expressing the feeling directly (e.g., "I am completely confused", "I do not know what to do in this case"), bodily actions (e.g., squinting; looking repeatedly at other students and at the screen).

A chi-square test of independence showed that the relation between these variables was significant, $\chi 2(1, N=1286)=124.497, p<0.01$. Students who were more confused were more likely to request help than were students who expressed less confusion. Phi value was 0.311 , indicating a moderate relation between interest and collaboration.

At the beginning of this episode, Dari (sitting on the left in Figure 6) refers to the lighted icons in the software and asks her classmate to hypothesize as to why all the icons light up when they press the square icon.

25 Dari: If this reminds you of the square, the square reminds you of what? Rhombus, right? (..3..) Now we look at the parallelogram. Afterwards we play. (Clicks the parallelogram icon and a parallelogram appears on the screen)

26 Roqa: (laughs and then inhales. She squints-(Figure 6a)) Parallel? (Looking at the parallelogram and then at Dari-(Figure 6b)), the shape of a broken door.

27 Dari: (Laughs)

28 Roqa: (Laughs) 
29 Dari: You mean the door of our classroom? (..2..) I want to ask you. Are its angles acute? Right? Obtuse?

30 Roqa: (Seems confused and Looks at Dari-(Figure 6c)) Right (..2..) acute (..2..) obtuse

a

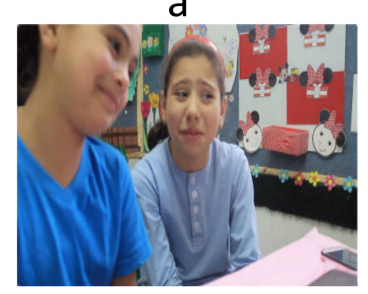

b

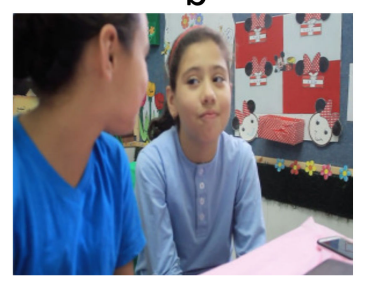

C

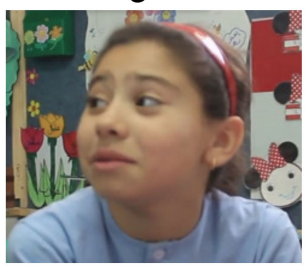

Figure 6. (a) Roqa (right) Laughs and then inhales. She squints skeptically at the screen; (b) looking at the parallelogram and then at Dari; (c) Seems confused and looks at Dari.

Roqa claimed the reflexive position of a confused learner during her learning about the characteristics of the parallelogram (R26-R30). This reflexive position of a confused learner was expressed in her inhaling and in her skeptical squint (R26). Having the previous position made her approach Dari, asking for her confirmation regarding what she says about the parallelogram, looking alternately at the parallelogram and at Dari (R26) and indicating her need of Dari's help. Throughout the above excerpt, Roqa kept the reflexive position of a confused learner who is in need of Dari's assistance. Being confused, she gave all the angle options for the characteristics of the parallelogram. The reflexive position of a confused learner was expressed in Roqa's facial expressions (puzzled eyes, slightly open mouth) (R30). This position made her continuously approach Dari for help, by asking her to either agree with the answers she gave or correct them (R30).

\subsection{Collaborator/Interested Relationship}

The following transcript discusses the relationship between the collaborator/interested constructs. Collaborator is a position construct, which we define as working with other learners to achieve a specific purpose. Indicators are: Verbal expressions (e.g., asking or answering questions, requesting or agreeing to do actions, agreeing with another member's statements), and bodily actions (e.g., looking together at the screen, controlling the mouse, pointing at the screen while looking at the classmate). 'Interested' is an emotion construct occurring when somebody gives his/her attention to something and wants to discover more about it. Indicators are: Expressing the feeling directly (e.g., "ohhh, this is really interesting", "wow, amazing"), asking to drag geometrical objects on the screen to explore properties, and bodily actions (e.g., opening the eyes and leaning forward towards the screen).

A chi-square test of independence showed that the relation between these variables was significant, $\chi 2(1, N=1286)=102.171, p<0.001$. Students with more interest were more likely to show collaboration than were students with less interest. Phi value was 0.276 , indicating a moderate relation between interest and collaboration.

The episode that follows illustrates the relationship between collaboration and interest. At the beginning of the episode, Hitam (the student on the left in Figure 7) and Pilo are exploring the common properties between a square and a rectangle. Hitam asks Pilo to give him the computer mouse.

42 Hitam: (Holding the mouse) Give me the mouse, it is my turn to explore (Figure 7a)

43 Pilo: You can take it!

44 Hitam: (looking with interest at the screen) This is a square (Hitam draws a square)

45 Pilo: Let's stretch it upward 
46 Hitam: (leaning forward and dragging the square to create a rectangle) this is a rectangle (smiles)

47 Pilo: Let's make a rectangle that is sleeping (a horizontal rectangle)

48 Hitam: (he tries to make the horizontal rectangle, without success

49 Pilo: (Pilo moves toward Hitam) Can you give me the mouse to show you how to do that? (Hitam hands the mouse to Pilo)
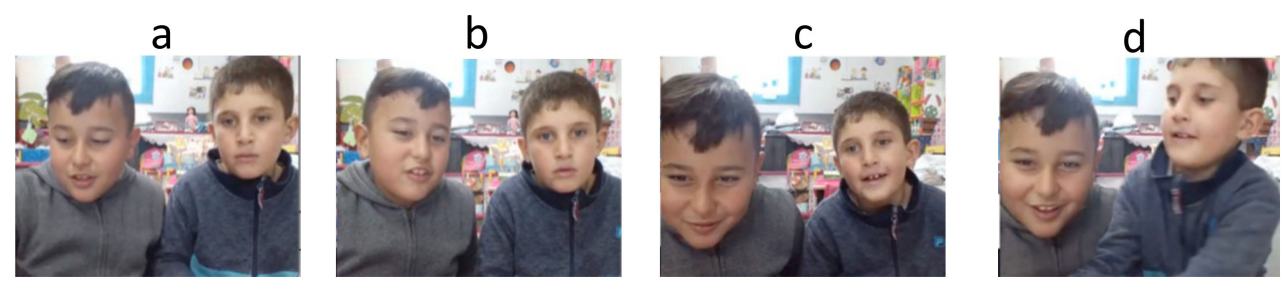

Figure 7. (a) Hitam (left) holding the mouse; (b) Hitam looking with interest at the screen; (c) Hitam leaning forward; (d) Pilo moving toward Hitam to take the mouse.

Hitam and Pilo claimed the position of collaborators (R42-R49), which is claimed reflexively and interactively. One indicator of this position in the excerpt above is represented by asking to do something and by performing the requested action, e.g., one asks to "give me the mouse" the other says "you can take it"; one asks to "stretch it upward" while the other drags the figure. Another indicator is the physical interaction between Hitam and Pilo; Hitam manipulates the mouse while Pilo looks at the screen, and both of them are occupied with exploring the square's properties, which indicates their interest in the exploration (Figure $7 \mathrm{~b}, \mathrm{c}$ ). Collaborating with Pilo, Hitam became interested in the mathematics in which the pair were engaged, i.e., exploring the common properties between the square and the rectangle. This interest is seen in Hitam dragging the square and creating a rectangle (R46), and trying to make a horizontal rectangle (R48). The position of collaborators and the accompanying interest were also realized in Pilo's movement toward Hitam to take the mouse and continue the exploration (R49). In addition, Pilo claimed the position of a collaborator with Hitam, expressing interest in the mathematical topic during the whole excerpt. The interest was expressed by his attentive gazing at the screen (Figure $7 \mathrm{a}-\mathrm{c}$ ) and leaning forward with his entire body (Figure 7c,d).

\section{Discussion}

In this study, we conducted qualitative and quantitative analysis of the relationships between positioning constructs and emotion constructs amongst pairs of elementary school students while learning geometry using digital tools. Quantitatively, strong relationships were found between leadership and confidence and between outsiderness and boredom. Moderate relationships were found between outsiderness and powerlessness, seeking help and confusion, and between collaboration and interest. Although some of the results are not unexpected, the method of confirming the relationships using a mixed method gives a robust basis for the relationship between positioning and emotions.

The relationship between leadership and confidence was noted by Axelrod [38], who says that a high level of confidence is essential for effective leadership and enables the leader to influence his or her collaborators or followers. We witnessed this influence in the present study by observing the learners who claimed the reflective positions of leaders of the learning pairs. This reflective position of the leader was facilitated by the confidence in the capability to engage in the geometric activity in which the pair was engaged. Additionally, based on the qualitative analysis, we found that the leadership-confidence relationship was two-directional, (i.e., not only that confidence leads to leadership but also that leadership leads to confidence). This observation adds another dimension to the relationship between positioning and emotions. Evans et al. [6] emphasizes positioning's influence upon emotions without considering emotions' potential impact on positioning. They express this influence when describing the structural phase of the discursive analysis: 
"The structural analysis provides us with an overall view of the positions available, the spaces within which emotion may arise and the roles that expression of emotion may play within a discourse" (p. 6). Thus, for Evans et al. [6], emotions need to be studied in the positioning context. We agree with them, but suggest the need to study the other direction, i.e., positioning in the emotional context.

The significant relationship between the reflective positioning of outsiderness and the boredom emotion is to be expected, as each of the constructs could lead to the other. The outsiderness positioning and the boredom emotion could result from the same phenomenon, namely little interest in the content [39]. For example, Roqa might have been disinterested in part of the geometrical topic that the group learned, e.g., the quadrilateral hierarchical relationships. This lack of interest made her claim a reflective position of outsider and thus become bored. Alternatively, the other direction could have prevailed, i.e., the disinterest made her bored, which resulted in her claiming a reflective position of an outsider to the learning of the group.

Another interpretation for the students' emotion of boredom could result from what [35] called qualitative underload and qualitative overload. Qualitative underload is the engagement with simple, repetitive and non-challenging tasks with low mental demands, which do not require the utilization of the student's skill. Qualitative overload is the engagement with highly challenging tasks that make demands of students, such as continuous attention, which they cannot keep. Fisher [39] reported that the students in his study gave numerous examples of feeling bored because they had difficulty keeping their attention on topics that they did not understand and/or found too difficult, and that the appropriateness of tasks can therefore be a cause of boredom.

As suggested by Fisher's study, the task given to the students in our study presented a greater challenge than Roqa could accommodate, which resulted in her outsiderness and related boredom. Therefore, to avoid boredom and the resulting outsiderness (or vice versa), we conclude that the design of the task should take into account the qualitative underload and overload the students might meet. It is likely that less challenging tasks would have interested her and helped her focus during the process of carrying out those tasks, as indicated by the interest and cooperation Roqa showed during other parts of the activity [40]. The present study did not come across cases of underload that resulted in boredom and outsiderness, perhaps because the tasks were not very easy even for high achieving participants as in the present study.

The relationship between outsiderness and powerlessness could be explained by the connection between personal control and interest, as noted by Deci [41], who asserts that personal control, together with feelings of competence, are major determinants of intrinsic interest in a task. Here, powerlessness indicates the opposite of personal control, which is expected to result in disinterest in learning, and thus outsiderness. In the case of Sawe and Ali, Sawe was the dominant member of the pair, which made Ali feel a lack of personal control over the learning process, and thus a powerlessness. It seems that this feeling resulted in his outsiderness. Another possible reason for Ali's outsiderness and powerlessness could be the task's qualitative overload, as mentioned above [39], which kept him positioned as an outsider.

In the present study we defined confusion as a state of uncertainty, or of finding something difficult to understand, which points at confusion as an epistemic or knowledge emotion [38]. According to D'Mello [42], confusion arises when there are inconsistencies in the information stream, which are accompanied or followed by the need for help to overcome them. This could be the case in the relationship between seeking help and confusion demonstrated in Roqa's behavior. For example, there was inconsistency in Roqa's knowledge about the parallelogram, as she considered it a broken door. This inconsistency made her approach Dari, seeking confirmation of why the shape in the screen is a parallelogram.

"Interest" was defined in this study as an emotion that occurs when students give their attention to something and want to discover more about it. Our results indicated a 
significant relationship between collaboration and interest. This finding corresponds to those of previous studies, which found that collaboration could increase students' interest. In this context, Foes [43] found that both student-directed and collaborative learning environments lead to a more engaged and interested student. It is worth noting that Hitam's emotions changed positively as a consequence of the pair's collaboration during the learning experiment. Hitam's familiarity with the geometrical shapes (square and rectangle) helped him collaborate with Pilo during the interaction. Moreover, the collaboration with Pilo made Hitam feel in control, he became more interested in discovering the properties of the geometric shapes.

\section{Implications and Limitations}

Interactive technology is suggested as means for motivating students' learning [44]. In this research, the interactive technological tool could be considered a knowledge construction mind tool, as it helped the participants explore the mathematical topic. In our case, the interactive knowledge construction mind tool influenced the participants' positioning and emotions in different ways and encouraged the emergence of certain positioning/emotion relationships. This influence came as a result of the potentiality of the knowledge construction mind tool to enable learning that takes into account "the range of symbolic and visual forms that enable construction, analysis and refinement of ideas" ([45], p. 9).

The influence of the technological tool came through action with the technological tool. Manipulating the objects on the screen via the mouse strengthened the leadership of the student who manipulated the objects. In contrast, not controlling the mouse tended to foster positions such as outsiderness. This suggests that active involvement in deciding what goes on in the computer interface may promote positions such as collaborator or leader, as well as emotions such as interest or confidence. It further suggests that the exclusive manipulation of the objects on the screen by one student may prompt negative positions and emotions in the rest. The influence of action with the technological tool on students' positions and emotions could result from the influence of this action on students' mathematical worldview, including their view of their "mathematical self" [46]. This view-of-the-self answers the question: What am I in relation to this mathematical behavior I am producing? ([46], p. 101). Using technology to produce mathematical objects influences the positions taken up by participants in the group, and the emotions that accompany the production and the positioning processes. This suggests that teachers must be aware of these impacts and take into consideration the interaction of the students with the technological tool, in order to positively affect their positioning and emotions.

Though our study did not focus explicitly on the teacher's role in determining students' positioning and emotions, but rather on the analysis of the positioning and emotions as students work independently in pairs, we nevertheless acknowledge that the teacher can play a central part in influencing students' academic performance [47], including the assigning of students' positioning, and thus also the shaping their emotions. In our case, the teacher's interventions and scaffolding focused primarily on changing undesirable positions within the student pairs. For example, in excerpt 2, the teacher intervened to encourage Roqa to be an insider and a collaborator. In doing so, the teacher interacted with the students through scaffolding actions: asking the students to perform specific actions, encouraging them to answer questions related to the activity, and encouraging them to collaborate. These interventions help enhance students' positions, promoting positive emotions, and avoid negative positions such as outsiderness and their attendant negative emotions, such as boredom. Further research is required to study whether the teacher's interventions moderate the positioning-emotion relationship.

The present research showed that some relationships between positioning and emotions are significant, while others are not. At the same time, it showed that the significant relationships vary in their strength. Although we analyzed a large number of student interactions, the focus on a small number of students might be considered one of the study's limitations. Moreover, it could be claimed that the results turned to be as one 
might expect, but the robust platform of the mixed method offers a highly valid comment. Further research of the relationships between positioning and emotions may find this most pertinent.

The personal characteristics of students were little taken into consideration in the present research. This little consideration came from the theoretical assumption of positions as not fixed, so the collaborator position, for example, could be the position of a student in one activity, but not in a different activity. Moreover, the influence of child's character or background would better be studied in a quantitative research that takes care of antecedent variables. We are aware that the personal characteristics of the students may affect the nature of their interaction and, as a result, the relationships between their positioning and emotions. Future research is also required to study the relationships between social constructs and affective constructs, as the present research addressed these relationships in the context of high-achieving learners. Specifically, future research is required to determine how the results of the present research compare to those of students with less confidence and proficiency in mathematics.

We conclude that more research is needed to deepen our understanding of these relationships, especially research that combines the two methodologies-the quantitative and the qualitative-incorporating quantitative research into the in-class study of students' interaction during the learning process. Quantitative research that takes care of antecedent variables could contribute to widening the scope of the present research, though not in the frame of the current discursive emotions framework, where positions are not fixed.

As an epilogue, the present study contributes to previous research that investigated the characteristics of the world of the learner. It attempts to study the components of this world. In the "The Hidden Lives of Learners", Nuthall [48] takes us into the undiscovered world of the learner. The text explores the three worlds which together shape this world: the public world of the teacher, the highly influential world of peers, and the student's own private world and experiences. Here, the technological tool is also influential in the world of the learner. What becomes clear is that just because a teacher, a text and a tool are there, does not mean students are learning. We need to study students' positions and emotions and the relationship between them to verify this learning.

Author Contributions: Conceptualization, O.S.; methodology, O.S. and W.D.; software, O.S. and W.D.; validation, O.S. and W.D.; formal analysis, W.D. and O.S.; investigation, O.S; resources, W.D.; data curation, O.S.; writing-original draft preparation, W.D. and O.S.; writing—review and editing, W.D. and O.S.; supervision, O.S.; project administration, O.S. All authors have read and agreed to the published version of the manuscript.

Funding: This research received no external funding.

Institutional Review Board Statement: Not applicable.

Informed Consent Statement: All participants signed an Informed Consent Statement.

Acknowledgments: The authors are grateful to all the students and the teacher for providing their time in conducting the current study.

Conflicts of Interest: The authors declare no conflict of interest.

\section{References}

1. Goldin, G.A. Perspectives on emotion in mathematical engagement, learning, and problem solving. In International Handbook of Emotions in Education. Routledge Handbooks Online; Alexander, P.A., Pekrun, R., Linnenbrink-Garcia, L., Eds.; Routledge: Abingdon, UK, 2014; pp. 391-415.

2. Pekrun, R. Emotions and Learning; The International Academy of Education \& UNESKO: Geneva, Switzerland, 2017.

3. Vanneste, P.; Oramas, J.; Verelst, T.; Tuytelaars, T.; Raes, A.; Depaepe, F.; Van den Noortgate, W. Computer Vision and Human Behaviour, Emotion and Cognition Detection: A Use Case on Student Engagement. Mathematics 2021, 9, 287. [CrossRef]

4. Dolcos, F.; Iordan, A.D.; Dolcos, S. Neural correlates of emotion-cognition interactions: A review of evidence from brain imaging investigations. J. Cogn. Psychol. 2011, 23, 669-694. [CrossRef]

5. Bartley, S.R.; Ingram, N. Parental modelling of mathematical affect: Self-efficacy and emotional arousal. Math. Educ. Res. J. 2018, 30, 277-297. [CrossRef] 
6. Evans, J.; Morgan, C.; Tsatsaroni, A. Discursive positioning and emotion in school mathematics practices. Educ. Stud. Math. 2006, 63, 209-226. [CrossRef]

7. Hannula, M.S. Exploring new dimensions of mathematics-related affect: Embodied and social theories. Res. Math. Educ. 2012, 14, 137-161. [CrossRef]

8. Skillmathing, K.; Bobis, J.; Martin, A.J. The "ins and outs" of student engagement in mathematics: Shifts in engagement factors among high and low achievers. Math. Educ. Res. J. 2020. [CrossRef]

9. Kim, C.; Park, S.W.; Cozart, J. Affective and motivational factors of learning in online mathematics courses. Br. J. Educ. Technol. 2014, 45, 171-185. [CrossRef]

10. Cho, M.H.; Heron, M.L. Self-regulated learning: The role of motivation, emotion, and use of learning strategies in students' learning experiences in a self-paced online mathematics course. Distance Educ. 2015, 36, 80-99. [CrossRef]

11. Daher, W.; Swidan, O.; Masarwa, A. Positioning and emotions in learning algebra: The case of high and middle achieving students. In Broadening the Scope of Research on Mathematical Problem Solving: A Focus on Technology, Creativity and Affect; Carreira, S., Amado, N., Jones, K., Eds.; Springer: Cham, Switzerland, 2018; pp. 525-540.

12. Bossér, U.; Lindahl, M. Students' positioning in the classroom: A study of teacher-student interactions in a socioscientific issue context. Res. Sci. Educ. 2019, 49, 371-390. [CrossRef]

13. Daher, W. A teacher's ideology and its impact on students' positioning in problem solving. Philos. Math. Educ. J. 2018, 34. Available online: https:/ / www.researchgate.net/publication/330351508 (accessed on 7 July 2021).

14. Lave, J.; Wenger, E. Situated Learning: Legitimate Peripheral Participation; Cambridge University Press: Cambridge, UK, 1991.

15. Harré, R.; Gillett, G. The Discursive Mind. Sage: Thousand Oaks, CA, USA, 1994.

16. Yamakawa, Y. The Impact of Teacher Positioning on Students' Opportunities to learn: A Case Study of an Elementary Mathematics Classroom. Doctoral Dissertation. 2014. Available online: http://d-scholarship.pitt.edu/21503/1/Yukari_YAMAKAWA_ dissertation.pdf (accessed on 10 June 2021).

17. Harré, R.; Moghaddam, F.M. Positioning theory. In the Discursive Turn in Social Psychology; Bozatzis, N., Dragonas, T., Eds.; Taos Institute Publications: Chagrin Falls, OH, USA, 2014; pp. 129-138.

18. Harré, R.; Slocum, N. Disputes as complex social events: On the uses of positioning theory. In The Self and Others: Positioning Individuals and Groups in Personal, Political, and Cultural Contexts; Harré, R., Moghaddam, F., Eds.; Praeger: Westport, CT, USA, 2003; pp. 123-136.

19. Yamakawa, Y.; Forman, E.A.; Ansell, E. The role of positioning in constructing an identity in a third grade mathematics classroom. In Investigating Classroom Interaction: Methodologies in Action; Kumpulainen, K., Hmelo-Silver, C.E., Cesar, M., Eds.; Sense Publishers: Rotterdam, The Netherlands, 2009; pp. 179-202.

20. Ritchie, S.M. Student positioning within groups during science activities. Res. Sci. Educ. 2002, 32, 35-54. [CrossRef]

21. Tait-McCutcheon, S.L.; Loveridge, J. Examining equity of opportunities for learning mathematics through positioning theory. Math. Educ. Res. J. 2016, 28, 327-348. [CrossRef]

22. Morgan, C.; Evans, J.; Tsatsaroni, A. Emotion in school mathematics practices: A contribution from discursive perspectives. In Proceedings of the Third International Conference Mathematics Education and Society, Helsingor, Denmark, 2-7 April 2002; pp. 400-413.

23. Jewitt, C.; Henriksen, B. Social Semiotic Multimodality. In Handbuch Sprache im Multimodalen Kontext; De Gruyter: Berlin, Germany, 2016; pp. 145-164.

24. Tomkins, S.S. Affect, Imagery and Consciousness; Springer: New York, NY, USA, 1963; Volume 2.

25. Daher, W.; Swidan, O.; Shahbari, J. Discursive positionings and emotions in a small group's learning of geometric definitions. In Proceedings of the Ninth Congress of the European Society for Research in Mathematics Education (CERME 9), Prague, Czech Republic, 4-8 February 2015; pp. 1160-1166.

26. Daher, W. Students' Positioning and Emotions in Learning Geometric Definition. J. Math. Educ. 2020, 11, 111-134. [CrossRef]

27. Daher, W. Discursive positionings and emotions in modelling activities. Int. J. Math. Educ. Sci. Tech. 2015, 46, 1149-1164. [CrossRef]

28. Daher, W.; Anabousy, A.; Jabarin, R. Metacognition, Positioning and Emotions in Mathematical Activities. Int. J. Res. Educ. Sci. 2018, 4, 292-303. [CrossRef]

29. NCTM. (n.d.) Exploring Properties of Triangles and Quadrilaterals. Available online: https://illuminations.nctm.org/Activity. aspx?id=6381 (accessed on 5 February 2020).

30. Jonassen, D.H.; Reeves, T.C. Learning with technology: Using computers as cognitive tools. In Handbook of Research for Educational Communications and Technology; Jonassen, D.H., Ed.; Macmillan: New York, NY, USA, 1996; pp. 693-719.

31. Wang, Z.; Lukowski, S.L.; Hart, S.A.; Lyons, I.M.; Thompson, L.A.; Kovas, Y.; Mazzocco, M.M.M.; Plomin, R.; Petrill, S.A. Is Math Anxiety Always Bad for Math Learning? The Role of Math Motivation. Psychol. Sci. 2015, 26, 1863-1876. [CrossRef] [PubMed]

32. Schukajlow, S.; Achmetli, K.; Rakoczy, K. Does constructing multiple solutions for real-world problems affect self-efficacy? Educ. Stud. Math. 2019, 100, 43-60. [CrossRef]

33. Schukajlow, S.; Rakoczy, K.; Pekrun, R. Emotions and motivation in mathematics education: Theoretical considerations and empirical contributions. ZDM Math. Educ. 2017, 49, 307-322. [CrossRef]

34. Sakr, M.; Jewitt, C.; Price, S. Mobile experiences of historical place: A multimodal analysis of emotional engagement. J. Learn. Sci. 2016, 25, 51-92. [CrossRef] 
35. Denzin, N.; Lincoln, Y. Handbook of Qualitative Research; Sage Publication Inc.: London, UK, 2000.

36. Stemler, S.E.; Tsai, J. Best practices in interrater reliability: Three common approaches. In Best Practices in Quantitative Methods; Osborne, J.W., Ed.; Sage: Thousand Oaks, CA, USA, 2008; pp. 29-49.

37. Rea, L.M.; Parker, R.A. Designing and Conducting Survey Research; Jossey-Boss: San Francisco, CA, USA, 1992.

38. Axelrod, R.H. Leadership and Self-Confidence. In Leadership Today: Practices for Personal and Professional Performance; Marques, J., Dhiman, S., Eds.; Springer: Cham, Switzerland, 2017; pp. 297-314.

39. Fisher, C.D. Boredom: Construct, Causes, and Consequences; Office of Naval Research: Arlington, VA, USA, 1987.

40. Locke, E.A.; Latham, G.P. New directions in goal-setting theory. Current Dir. Psychol. Sci. 2006, 15, 265-268. [CrossRef]

41. Deci, E.L. Intrinsic Motivation; Plenum Press: New York, NY, USA, 1975.

42. D'Mello, S.; Lehman, B.; Pekrun, R.; Graesser, A. Confusion can be beneficial for learning. Learn. Instr. 2014, 29, 153-170. [CrossRef]

43. Foes, P.; Shaffstall, K.; Thompson-Benton, A.; Turnbow, C. What are the effects of democratic classrooms? In Widening the Circle: Seeking Inclusive Education; An exploration of research, Conference Proceedings of Annual Presentation of Master's Papers; The Evergreen State College: Tacoma, WA, USA, 2014; pp. 95-136.

44. Bolívar-Chávez, O.-E.; Paredes-Labra, J.; Palma-García, Y.-V.; Mendieta-Torres, Y.-A. Educational Technologies and Their Application to Music Education: An Action-Research Study in an Ecuadorian University. Mathematics 2021, 9, 412. [CrossRef]

45. McLoughlin, C.; Krakowski, K. Technological tools for visual thinking: What does the research tell us. In Apple University Consortium Academic and Developers Conference; Apple University Consortium (AUC): Townsville, QLD, Australia, 2001; pp. 128-139.

46. Pea, R.D. Cognitive technologies for mathematics education. Cogn. Sci. Math. Educ. 1987, 11, 89-122.

47. Trujillo-Torres, J.-M.; Hossein-Mohand, H.; Gómez-García, M.; Hossein-Mohand, H.; Hinojo-Lucena, F.-J. Estimating the Academic Performance of Secondary Education Mathematics Students: A Gain Lift Predictive Model. Mathematics 2020, 8, 2101. [CrossRef]

48. Nuthall, G. The Hidden Lives of Learners; Nzcer Press: Wellington, New Zealand, 2007. 